\title{
Differences in spontaneous breathing pattern and mechanics in patients with severe COPD recovering from acute excerbation
}

\author{
M. Vitacca, R. Porta, L. Bianchi, E. Clini, N. Ambrosino
}

\begin{abstract}
Differences in spontaneous breathing pattern and mechanics in patients with severe COPD recovering from acute excerbation. M. Vitacca, R. Porta, L. Bianchi, E. Clini, N. Ambrosino. (C) ERS Journals Ltd 1999.

ABSTRACT: The aims of this study were to assess spontaneous breathing patterns in patients with chronic obstructive pulmonary disease (COPD) recovering from acute exacerbation and to assess the relationship between different breathing patterns and clinical and functional parameters of respiratory impairment.

Thirty-four COPD patients underwent assessment of lung function tests, arterial blood gases, haemodynamics, breathing pattern (respiratory frequency $(f \mathrm{R})$, tidal volume $(V T)$, inspiratory and expiratory time ( $t \mathrm{I}$ and $t \mathrm{E})$, duty cycle $\left.(t \mathrm{I} / \mathrm{ttot}), V_{\mathrm{T}} / \mathrm{tI}\right)$ and mechanics (oesophageal pressure (Poes), work of breathing (WOB), pressure-time product and index, and dynamic intrinsic positive end-expiratory pressure (PEEPi,dyn)).

According to the presence (group 1) or absence (group 2) of Poes swings during the expiratory phase (premature inspiration), $20(59 \%)$ patients were included in group 1 and $14(41 \%)$ in group 2. Premature inspirations were observed $4.5 \pm 6.4$ times $\mathrm{min}^{-1}$ (range 1-31), i.e. $20 \pm 21 \%(3.7-100 \%)$ of total $f R$ calculated from $V T$ tracings. In group 1 the coefficient of variation in $V_{T}, t E, t I / t$ tot, PEEPi,dyn, Poes and WOB of the eight consecutive breaths immediately preceding the premature inspiration was greater than that of eight consecutive breaths in group 2 . There were no significant differences in the assessed parameters between the two groups in the overall popu-lation, whereas patients with chronic hypoxaemia in group 1 showed a more severe impairment in clinical conditions, mechanics and lung function than hypoxaemic patients in group 2.

In spontaneously breathing patients with chronic obstructive pulmonary disease recovering from an acute exacerbation, detectable activity of inspiratory muscles during expiration was found in more than half of the cases. This phenomenon was not associated with any significant differences in anthropometric, demographic, physiological or clinical characteristics.
\end{abstract}

Eur Respir J 1999; 13: 365-370. S. Maugeri Foundation IRCCS, Lung
Function Unit, Pulmonary Dept, Medical Centre of Gussago (BS), Italy.

Correspondence: M. Vitacca

Fondazione S. Maugeri IRCCS

Centro Medico di Gussago

25064 Gussago (BS)

Italy

Fax 39030252171

Keywords: Acute respiratory failure chronic respiratory insufficiency ineffective efforts

mechanical ventilation

Received: March 91998

Accepted after revision October 11998
Many studies have shown breath-to-breath variations in the spontaneous breathing pattern of healthy subjects and patients with pulmonary diseases [1-17]. Periodic fluctuations have been observed in the ventilatory parameters of awake adult humans in eupnoea [1], at high altitude [3] and in newborn infants [4]. These fluctuations have been explained as unrelated random noise superimposed on the output of the respiratory central controller system [8]. No difference in intraindividual variability of the breathing pattern was found between different groups of stable patients with chronic obstructive pulmonary disease (COPD) with varying degrees of mechanical and arterial blood gas impairment [17]. All of these studies were performed by analysing flow and/or volume tracings.

The spontaneous breathing pattern has been less studied in severe COPD patients recovering from exacerbations. Differences in spontaneous breathing pattern might be found in these patients and these differences might be related to their clinical and physiological characteristics.

For editorial comments see page 236
Therefore, the aim of this study was to analyse the clinical and functional characteristics of such patients according to differences in the breathing pattern based on oesophageal measurements.

\section{Patients and methods}

The Ethical Committee of the Medical Centre of Gussago, S. Maugeri Foundation, approved the study, which was conducted according to the declaration of Helsinki. Patients gave their informed consent to participate in the study.

\section{Patients}

Thirty-four consecutive patients admitted to the Intermediate Intensive Care Unit and recovering from a recent episode of a noninfectious exacerbation of COPD entered the study. The diagnosis of COPD was made according to the American Thoracic Society (ATS) guidelines [18]. When the patients were recruited for this study, they were 
all in a stable condition, as assessed by stability in blood gas values, $\mathrm{pH}(>7.35)$ and haemodynamics, they did not need sympathomimetics and did not suffer from a low cardiac output. All patients had been free from exacerbation for at least 1 week. Patients with other organ failure, cancer or inability to co-operate were excluded from the study. While in their stable condition before the exacerbation, 25 patients were on long-term oxygen therapy (LTOT) (five of whom were also on domiciliary long-term mechanical ventilation) and all patients were receiving treatment with inhaled bronchodilators but no systemic or inhaled steroids. During their exacerbation all patients had been treated with standard medical therapy including antibiotics when requested, systemic steroids, inhaled bronchodilators and oxygen. Twenty-four patients had also been treated with mechanical ventilation (16 invasively through tracheotomy and eight via a mask). The 16 patients undergoing invasive mechanical ventilation were still tracheostomized but breathing spontaneously at the time of the study. The demographic, anthropometric and clinical characteristics and arterial blood gases of patients at enrolment are show in table 1.

\section{Measurements}

Pulmonary function and arterial blood gases. Dynamic and static lung volumes were measured by means of a constant-volume body plethysmograph (CAD-NET system 1085; Medical Graphic Corp., St Paul, MN, USA). The predicted values of QuANJER [19] were used. Arterial oxygen and carbon dioxide tensions $\left(\mathrm{Pa}, \mathrm{O}_{2}, \mathrm{~Pa}_{\mathrm{a}} \mathrm{CO}_{2}\right)$ and $\mathrm{pH}$ were assessed by means of an analyser (ABL 300; Radiometer, Copenhagen, Denmark) on blood samples drawn from the radial artery while patients in the sitting position breathed at an inspiratory oxygen fraction $\left(F \mathrm{I}, \mathrm{O}_{2}\right)$ sufficient to maintain a target arterial oxygen saturation $\left(\mathrm{Sa}_{\mathrm{a}} \mathrm{O}_{2}\right)$ between 90 and $92 \%$.

Table 1. - Anthropometric, demographic, arterial blood gases, clinical and haemodynamic characteristics

\begin{tabular}{|c|c|c|c|}
\hline & Total & Group 1 & Group 2 \\
\hline Patients $\mathrm{n}$ & 34 & 20 & 14 \\
\hline Age yrs & $65 \pm 8$ & $66 \pm 4$ & $65 \pm 8$ \\
\hline Weight $\mathrm{kg}$ & $66 \pm 20$ & $68 \pm 5$ & $62 \pm 7$ \\
\hline Tracheostomized & $16(47)$ & $11(55)$ & $5(36)$ \\
\hline Ventilated & $24(70.5)$ & $14(70)$ & $10(71)$ \\
\hline ICU stay days & $14 \pm 10$ & $15 \pm 4$ & $14 \pm 6$ \\
\hline Hospital stay days & $30 \pm 17$ & $31 \pm 12$ & $27 \pm 10$ \\
\hline$P \mathrm{a}, \mathrm{O}_{2} / F \mathrm{I}, \mathrm{O}_{2}$ & $281 \pm 61$ & $270 \pm 100$ & $262 \pm 120$ \\
\hline $\mathrm{Pa}_{1} \mathrm{CO}_{2} \mathrm{kPa}$ & $6.8 \pm 1.6$ & $6.7 \pm 0.5$ & $6.8 \pm 0.6$ \\
\hline $\mathrm{pH}$ & $7.41 \pm 0.05$ & $7.41 \pm 0.02$ & $7.41 \pm 0.01$ \\
\hline Mortality & $2(6)$ & $1(5)$ & $1(7)$ \\
\hline LTOT & $25(74)$ & $14(70)$ & $11(78)$ \\
\hline Home MV & $5(15)$ & $2(10)$ & $3(21)$ \\
\hline sPAP mmHg & $51 \pm 11$ & $43 \pm 10$ & $37 \pm 9$ \\
\hline RVD mm & $34 \pm 4$ & $35 \pm 5$ & $33 \pm 6$ \\
\hline LVEF \% & $59 \pm 6$ & $58 \pm 7$ & $37 \pm 10$ \\
\hline
\end{tabular}

Data are shown as mean \pm SD or $\mathrm{n}(\%)$. ICU: intensive care unit; $\mathrm{Pa}_{\mathrm{a}} \mathrm{O}_{2}$ : arterial oxygen tension; $\mathrm{FI}, \mathrm{O}_{2}$ : inspiratory oxygen fraction; $\mathrm{Pa}_{\mathrm{a}} \mathrm{CO}_{2}$ : arterial carbon dioxide tension; LTOT: long-term oxygen therapy; MV: mechanical ventilation; sPAP: systolic pulmonary arterial pressure; RVD: right ventricular diameter; LVEF: left ventricular election fraction.
Respiratory muscle function. The respiratory muscle strength was assessed by measuring maximal inspiratory and expiratory pressures (MIP and MEP, respectively) at the level of functional residual capacity (FRC) and total lung capacity (TLC), respectively, according to the method of Black and HyatT [20], using a respiratory module system (Medical Graphic Corp.). Patients performed a minimum of three manoeuvres with at least a 1 -min interval between efforts until two acceptable values not differing from each other by $>5 \%$ were obtained. The best value was recorded. Despite the possibility of underestimating results owing to leakage of air around the cannula and resistance created by the cannula itself, in tracheostomized patients spirometry and respiratory muscle function evaluation were performed through a mouthpiece with the simultaneous closure of the external hole of a fenestrated and uncuffed cannula.

Breathing pattern and respiratory mechanics. For the experimental procedure of this study, flow $\left(V^{\prime}\right)$ and proximal airway pressure $(P$ aw $)$ were measured using a pneumotachograph/pressure transducer (Bicore, Irvine, CA, USA) connected to a mouthpiece or, in the tracheostomized patients, to the external hole of the cuffed cannula. Volume $(V)$ was obtained by numerical integration of the flow signal. Changes in pleural pressure $(P \mathrm{pl})$ were estimated from changes in oesophageal pressure $(P$ oes $)$, by means of the balloon-catheter technique, with an oesophageal balloon-catheter connected to a differential pressure transducer $\left( \pm 140 \mathrm{cmH}_{2} \mathrm{O}\right.$; Bicore $)$. Maximal static inspiratory $P_{\text {oes }}\left(P_{\text {oes,max }}\right)$ was assessed by means of a Müller manoeuvre during a maximal inspiratory effort generated after manual occlusion of the flow transducer starting from FRC. The subjects were verbally encouraged to achieve maximal strength. The highest value (most negative $\left.P_{\text {oes}}\right)$ of three tests was considered in data analysis [21].

Haemodynamic function. Routine echo-Doppler evaluation (left ventricular ejection fraction (LVEF), right ventricular diameter (RVD) and systolic pulmonary arterial pressure (sPAP)) was performed using an echograph (SPR 8000; ESAOTE, Italy).

Clinical outcome. The number of days under mechanical ventilation, duration of hospital stay, mortality, comorbidity and need for LTOT or home mechanical ventilation were recorded from the hospital registers.

\section{Data analysis}

All signals from Bicore transducers were digitized by an analogue-to-digital converter and sent to an IBM compatible 486 personal computer at a sampling frequency of $100 \mathrm{~Hz}$. The subsequent analysis was performed using a software package (Computo; Elekton Agliano Terme, Italy). Tidal volume $(V \mathrm{~T})$, respiratory frequency $(f \mathrm{R})$ and minute ventilation $\left(V^{\prime} \mathrm{E}\right)$ were computed from the volume signal. Total cycle duration ( $t$ tot), inspiratory and expiratory time ( $t \mathrm{I}$ and $t \mathrm{E}$, respectively) and $t \mathrm{I} / t$ tot ratio were calculated from the flow signal, as average values from 1-min continuous records of flow and volume. Dynamic intrinsic positive end-expiratory pressure (PEEPi,dyn) was measured 
a)

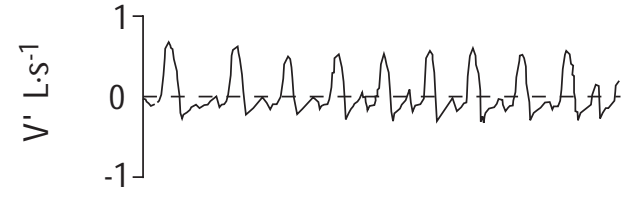

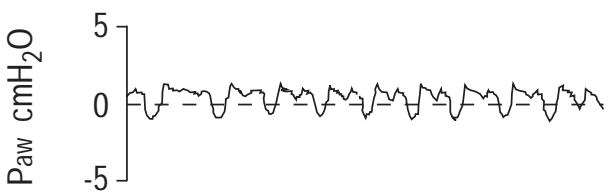
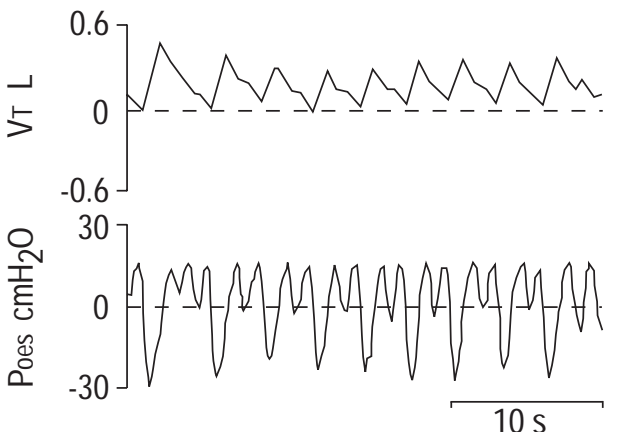

b)
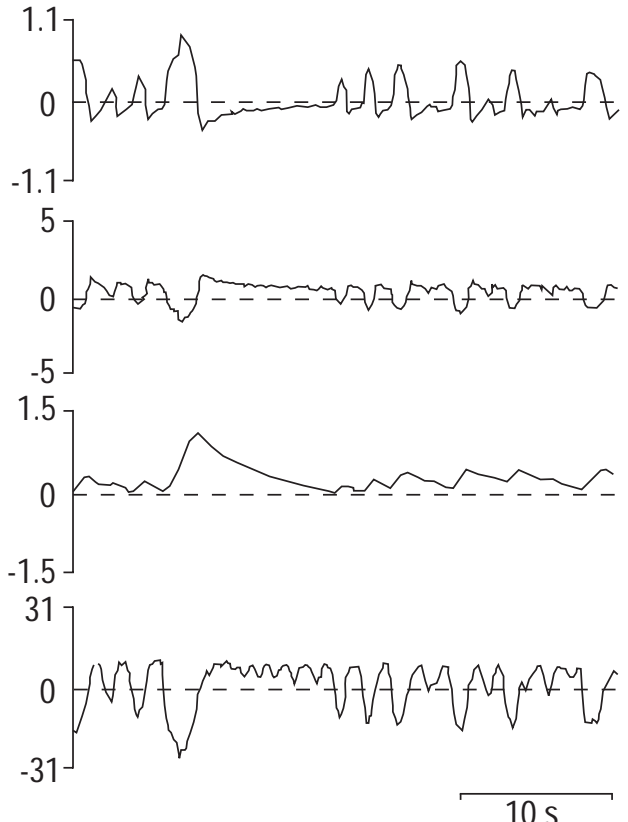

Fig. 1. - Polygraphic recording in two representative patients of group 1, showing airflow $\left(V^{\prime}\right)$, airway pressure $(P$ aw $)$, tidal volume $(V \mathrm{~T})$ and oesophageal pressure $\left(P_{\mathrm{oes}}\right)$. a) The patient showed a $P_{\text {oes }}$ swing $/ V$ T ratio of 1:2, with a detectable flow corresponding to each $P$ oes swing. b) The patient recorded a deep sigh followed by a long expiration, during which premature inspirations were detectable without any flow signal.

as the negative deflection in $P$ oes from the onset of inspiratory effort to the onset of inspiratory flow. Changes in the magnitude of the effort of the inspiratory muscles were estimated from changes in Poes, as described previously. The pressure-time product of the inspiratory muscles (PTPoes) was measured as the area enclosed within $P_{\text {oes }}$ and the chest wall static recoil pressure $\left(P_{\mathrm{cw}, \mathrm{st}}\right)-$ time curve over $t \mathrm{t}$, taking into account the PEEPi,dyn. The $P$ cw,st-time curve was extrapolated to the predicted value of chest wall compliance $(C \mathrm{cw}, \mathrm{st})$. Thus the slope of the $P$ cw,st-time relation was $(\Delta V \mathrm{~T} / C \mathrm{cw}, \mathrm{st}) / \Delta t \mathrm{I}$. PTPoes was multiplied by $f \mathrm{R}$ and expressed in $\mathrm{cmH}_{2} \mathrm{O} \cdot \mathrm{s} \cdot \mathrm{min}^{-1}$. Inspiratory work of breathing (WOB), expressed as $\mathrm{J} \cdot \mathrm{L}^{-1}$, was calculated from the area subtended by the $P$ oes developed during inspiration and the relaxation curve of the chest wall (estimated $C \mathrm{cw}, \mathrm{st}$ equal to $200 \mathrm{~mL} \cdot \mathrm{cmH}_{2} \mathrm{O}^{-1}$ ). Transpulmonary $(P \mathrm{~L})$ pressure was obtained by subtracting $P_{\text {oes }}$ from $P$ aw. Dynamic compliance $(C \mathrm{~L}$,dyn) was calculated as follows: $C \mathrm{~L}$,dyn $=V \mathrm{~T} /(P \mathrm{~L}, 1-P \mathrm{~L}, 2)$, where $P \mathrm{~L}, 1$ is transpulmonary pressure at maximum volume zero flow and $P$ L, 2 is transpulmonary pressure at minimum volume zero flow. The pressure time index (PTI) was calculated as mean $P_{\text {oes}} /$ $P$ oes, max $\times t \mathrm{I} / t$ tot. The reliability and accuracy of the Bicore CP-100 pulmonary device have been demonstrated previously $[22,23]$.

The study was conducted after $30-45 \mathrm{~min}$ of quiet breathing, when the patients had become confident with the instrumentation. Care was taken to ensure that the patients felt comfortable. A 180 -s recording of spontaneous breathing in a semirecumbent position was analysed after at least a further $2 \mathrm{~min}$ of spontaneous breathing with the pneumotachograph switched on. When recordings appeared free from artefacts (e.g. cough, oesophageal contractions or swallowing), airway pressure, airway flow and $P$ oes were transmitted to the monitor and recorded for 180 s. The data used for statistical measurements were col- lected as the average data of at least five breathing acts, eliminating those affected by artefactual variations in $P$ oes. According to the presence of one or more inspiratory efforts as assessed by $P_{\text {oes }}$ swings during expiration (premature inspiration), patients were divided into group 1, in whom this observation was made (fig. 1), and group 2, in whom this phenomenon was not observed. In group 1, the coefficient of variation $(\mathrm{CV})$ of parameters studied was calculated as $\mathrm{SD} /$ mean $\%$ on the eight consecutive breaths immediately preceding the one showing a $P_{\text {oes }}$ swing during the expiratory phase; in group 2, $\mathrm{CV}$ was assessed on the first eight consecutive breaths of recording (fig. 2).

\section{Statistical analysis}

Data are shown as mean \pm SD. Differences between groups were evaluated by unpaired t-tests. Regression analysis (Spearman) was used to assess relationships between the $\mathrm{CV}$ of the breathing pattern, mechanics and impairment indices.

\section{Results}

Twenty (59\%) patients were included in group 1 and 14 $(41 \%)$ in group 2 . Figure 1 shows two representative patients from group 1 with prolonged $t \mathrm{E}$, during which $P_{\mathrm{oes}}$ swings were observed. Premature inspirations were observed $4.5 \pm 6.4$ times $\cdot \mathrm{min}^{-1}$ (range 1-31), i.e. $20 \pm 21 \%$ $(4-100 \%)$ of $f \mathrm{R}$ calculated on $V \mathrm{~T}$. In figure la the representative patient showed a 1:2 $P_{\text {oes }}$ swing $/ V$ T ratio with a detectable flow corresponding to each $P_{\text {oes }}$ swing. Figure $1 \mathrm{~b}$ shows the one patient (out of 20) with a deep sigh followed by a long expiration, during which premature inspirations were detectable without any flow signal. In any instance, $f \mathrm{R}$ measured on the $P$ oes swing was greater than when measured on the $V \mathrm{~T}$ tracing. 
a)

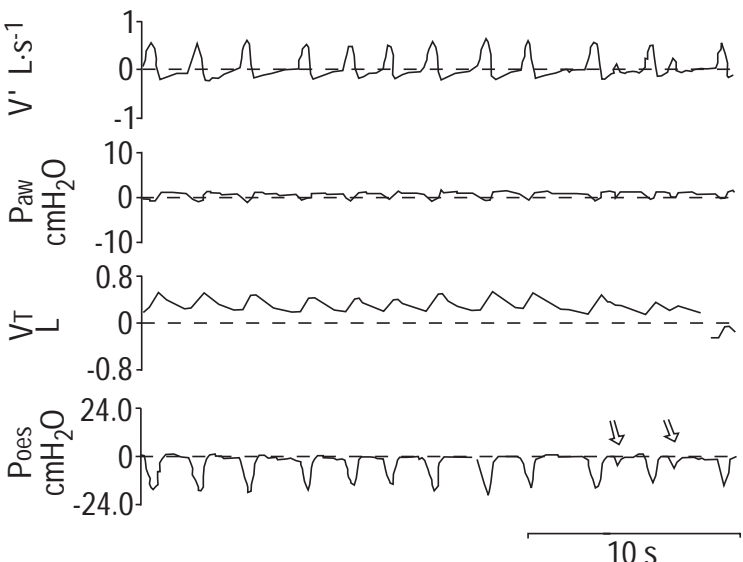

b)

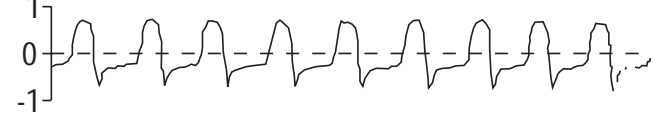

10

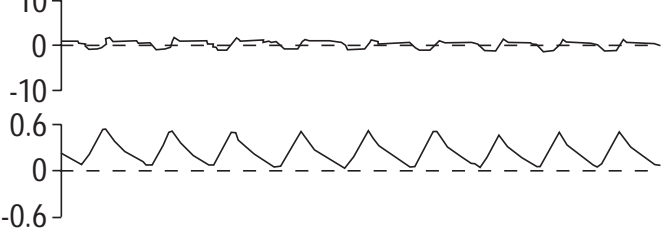

15

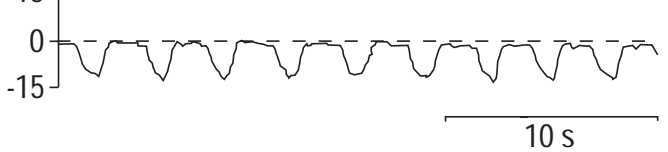

Fig. 2. - Polygraphic recordings of a) the eight consecutive breaths immediately preceding a premature inspiration in a representative patient of group 1 and b) the first eight consecutive breaths of recording in a representative patient of group 2 . Arrows in a) indicate premature inspirations. $V^{\prime}$ : airflow; $P$ aw: airway pressure; $V$ T: tidal volume; $P_{\text {oes: }}$ oesophageal pressure.

Table 1 shows the anthropometric, demographic, clinical and haemodynamic characteristics and arterial blood gases of all patients in study, as well as according to the two groups. No significant difference was observed between the two groups. Patients of both groups showed a low inhospital mortality, increased level of sPAP and reduced LVEF. Patients on LTOT were similarly distributed in the two groups.

Lung function, breathing pattern and mechanics are shown in table 2. Again, no significant difference was found between the two groups. Patients in both groups showed a detectable PEEPi,dyn, reduced dynamic volume, increased static volumes and reduced respiratory muscle strength.

Table 3 shows the mean $\mathrm{CV}$ of the breathing pattern and mechanics in the two groups. Patients in group 1 showed a significantly greater $\mathrm{CV}$ in PEEPi,dyn, inspiratory muscle function as assessed by WOB and $P_{\mathrm{oes}}$, and breathing pattern. Regression analysis showed the best relationships between the number of premature inspirations and the CV of $t \mathrm{E}(\mathrm{r}=0.80, \mathrm{p}<0.0001)$, whereas no significant relationship was found between the $\mathrm{CV}$ of the breathing pattern and of mechanics and impairment in mechanics, arterial blood gases, inspiratory muscle function or demographics.

Chronically hypoxaemic patients in group 1 requiring LTOT, when in a stable state before their exacerbation, showed more severe airway obstruction (as assessed by forced vital capacity (FVC), forced expiratory volume in one second (FEV1) and reduction in inspiratory muscle strength (as assessed by MIP)) than chronically hypoxaemic patients in group 2 (table 4). Patients in group 1 also had a higher $f \mathrm{R}$ and PTPoes.

\section{Discussion}

This study shows that detectable activity of inspiratory muscles (as assessed by $P$ oes swings) during expiration may be found in a proportion of spontaneously breathing COPD patients recovering from an acute exacerbation of their disease. Patients showing this phenomenon did not differ regarding the level of impairment in clinical status, mechanics, lung function and arterial blood gases from patients without this event. The subgroup of chronically hypoxaemic patients with premature inspirations showed a more severe level of impairment in respiratory conditions than the hypoxaemic patients in group 2.

Many studies have assessed breathing pattern by analysing flow and/or volume recordings both in normal subjects and in patients with different respiratory diseases [1-17]. Neuromechanical reflexes, upper airway mechanoreceptors, a "short-term memory" property of the central respiratory pattern generator [2], disturbances in $\mathrm{Pa}_{\mathrm{a}} \mathrm{CO}_{2}$ [10], respiratory impedance and resistive loading [7, 9] were all reported to contribute to breath-to-breath ventilatory variations in normal subjects. Mechanical impairment was found to be a cause of variability in the timing of breathing in COPD patients [11]. Although LOVERIDGE et al. [16] showed no significant differences in breathing pattern variability between COPD groups of different severity, the effect of chronic respiratory insufficiency on breathing variability is still discussed. Indeed, it has been reported that timing is variable in both hypercapnic [14] and hypoxaemic nonhypercapnic [12] COPD patients compared with normal control subjects. LOVERIDGE et al. [15] found that the presence of chronic respiratory insufficiency did not alter the variability of the resting breathing pattern, but Wolkove et al. [13] suggested opposite results.

To the authors' knowledge, no previous study has evaluated breathing pattern assessing inspiratory muscle activity. In this study, it was found that in COPD patients recovering from an episode of exacerbation, $f \mathrm{R}$ as assessed

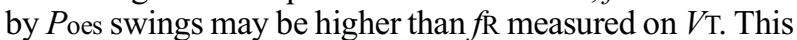
may provide some warning when evaluating respiratory frequency from the expired $V \mathrm{~T}$ at a patient's bedside. Indeed, in this study the assessment of $P$ oes swing allowed 10 out of 20 patients with $f \mathrm{R}>25$ breaths $\cdot \mathrm{min}^{-1}$ to be detected, compared with five patients with $f \mathrm{R}>25$ breath$\mathrm{s} \cdot \mathrm{min}^{-1}$ when detected by means of the evaluation of $V \mathrm{~T}$. Tachypnoea and a high $f \mathrm{R}$ to $V \mathrm{~T}$ ratio are considered to be signs of respiratory distress, impending inspiratory muscle fatigue and weaning failure from mechanical ventilation [24]. The evaluation of $f \mathrm{R}$ on the tracings of $V \mathrm{~T}$ may result in the underestimation of the real respiratory drive of patients such as those in the present study recovering from an acute exacerbation of their disease. 
Table 2. - Breathing patterns, lung function and mechanics

\begin{tabular}{|c|c|c|c|}
\hline & Total & Group 1 & Group 2 \\
\hline tients $\mathrm{n}$ & 34 & 20 & 14 \\
\hline & $384 \pm 1$ & $387 \pm$ & $381 \pm 140$ \\
\hline$f \mathrm{R}$ breaths $\cdot \mathrm{min}^{-1}$ & $20 \pm 5$ & $21 \pm 5$ & $18 \pm 5$ \\
\hline$t \mathrm{I} /$ tot & $0.36 \pm 0.06$ & $0.37 \pm 0.02$ & $0.35 \pm 0.03$ \\
\hline$V \mathrm{~T} / t \mathrm{I} \mathrm{L} \cdot$ & $0.35 \pm 0.11$ & $0.36 \pm 0.08$ & $0.32 \pm 0.08$ \\
\hline$V^{\prime} \mathrm{E} \mathrm{L} \cdot \mathrm{min}^{-1}$ & $7.2 \pm 2.6$ & $7.8 \pm 3$ & $6.3 \pm 1.8$ \\
\hline$f \mathrm{R} / V \mathrm{~T}$ breaths $\cdot \min ^{-1} \cdot \mathrm{L}^{-1}$ & $65 \pm 40$ & $72 \pm 44$ & $55 \pm 31$ \\
\hline MIP $\mathrm{cn}$ & $42 \pm$ & $39=$ & $44 \pm 12$ \\
\hline MEP & $82 \pm$ & $83 \pm$ & $82 \pm 15$ \\
\hline & $30=$ & 28 & $36=$ \\
\hline $\mathrm{F}$ & $43=$ & $42=$ & 46 \\
\hline & 176 & 172 & 169 \\
\hline TLC & $101=$ & $100 \pm$ & $99 \pm 25$ \\
\hline $\mathrm{RV} / \mathrm{TL}$ & 2 & $64 \pm$ & $65 \pm 13$ \\
\hline & & 13 & $14 \pm 7$ \\
\hline Poes & $45 \pm$ & $47 \pm 10$ & $40 \pm 12$ \\
\hline$P 0.1 \mathrm{c}$ & $1.62 \pm 0.84$ & $1.69 \pm 1$ & $1.52 \pm 2$ \\
\hline$P 0.1 / P_{\text {oes }}$, max & $0.04 \pm 0.02$ & $0.04 \pm 0.02$ & $0.04 \pm 0.03$ \\
\hline$P 0.1 / V \mathrm{~T} / t \mathrm{I} \mathrm{cmH}_{2} \mathrm{O} \cdot \mathrm{mL}^{-1} \cdot \mathrm{s}$ & $5.0 \pm 2.7$ & $5.1 \pm 0.2$ & $4.8 \pm 0.2$ \\
\hline WOBoes $J$ & $1.13 \pm 0.56$ & $1.11 \pm 0.02$ & $1.16 \pm 0.10$ \\
\hline$C \mathrm{~L}, \mathrm{dy}$ & $98 \pm 77$ & $109 \pm 67$ & $82 \pm 88$ \\
\hline PEEPi,dyn & $3.04 \pm 2.97$ & $2.68 \pm 2$ & $3.59 \pm 2$ \\
\hline PTPoes & $225 \pm 114$ & $229 \pm 99$ & $220 \pm 87$ \\
\hline PTI & $0.11 \pm 0.07$ & $0.11 \pm 0.08$ & $0.13 \pm 0.06$ \\
\hline
\end{tabular}

Data are shown as mean $\pm \mathrm{SD} . V \mathrm{~T}$ : tidal volume; $f \mathrm{R}$ : respiratory frequency; $t \mathrm{I} / t_{\text {tot: }}$ duty cycle; $V \mathrm{~T} / t \mathrm{I}$ : mean inspiratory flow; $V^{\prime} \mathrm{E}$ : minute ventilation; MIP: maximal inspiratory pressure; MEP maximal expiratory pressure; $\mathrm{FEV} 1$ : forced expiratory volume in one second; FVC: forced vital capacity; RV: residual volume; TLC: total lung capacity; $P_{\text {oes: }}$ oesophageal pressure; $P_{\text {oes,max }}$ maximal $P_{\text {oes; }} P_{0.1}$ : occlusion pressure; WOBoes: oesophageal work of breathing: $C \mathrm{~L}$,dyn: dynamic compliance; PEEPi,dyn: dynamic intrinsic positive end-expiratory pressure; PTPoes: pressure-time product of the inspiratory muscles; PTI: pressuretime index.

At least on theoretical grounds, the isolated analysis of $P$ oes cannot exclude that negative $P_{\text {oes }}$ swings might be attributed to a relaxation of the abdominal muscles and not to an active inspiratory contraction. Nevertheless, there is some confidence that this phenomenon is an inspiration because (as can be seen in the representative case in fig. 1a and in the portion following the sigh in fig. 1b) the higher the airflow the greater the $P$ oes swings; this fact fits poorly with an expiratory relaxation. Furthermore, the presence of

Table 3. - Significant differences in coefficients of variation of mechanics and breathing pattern in the two groups of patients

\begin{tabular}{lccl}
\hline & Group 1 & Group 2 & p-value \\
\hline Subjects n & 20 & 14 & \\
PEEPi,dyn & $0.33 \pm 0.15$ & $0.20 \pm 0.09$ & $<0.05$ \\
WOB & $0.26 \pm 0.10$ & $0.13 \pm 0.06$ & $<0.005$ \\
$P$ oes & $0.16 \pm 0.09$ & $0.06 \pm 0.02$ & $<0.005$ \\
$V \mathrm{~T}$ & $0.14 \pm 0.08$ & $0.09 \pm 0.02$ & $<0.01$ \\
$t \mathrm{E}$ & $0.34 \pm 0.13$ & $0.08 \pm 0.05$ & $<0.005$ \\
$t \mathrm{I} /$ tot & $0.14 \pm 0.08$ & $0.08 \pm 0.02$ & $<0.01$ \\
\hline
\end{tabular}

Data are shown as mean \pm SD. PEEPi,dyn: dynamic intrinsic positive end-expiratory pressure; WOB: work of breathing; $P_{\text {oes: }}$ : oesophageal pressure; $V \mathrm{~T}$ : tidal volume; $t \mathrm{E}$ : expiratory time; $t \mathrm{I} /$ tot: duty cycle.
Table 4. - Anthropometric, arterial blood gases, breathing pattern, mechanic, spirometric and clinical characteristics of patients on long-term oxygen therapy when in a stable state before their exacerbation

\begin{tabular}{|c|c|c|c|}
\hline & Group 1 & Group 2 & p-value \\
\hline Subjects & $14(70)$ & $11(78)$ & NS \\
\hline Age yrs & $67 \pm 8$ & $63 \pm 8$ & $<0.05$ \\
\hline Tracheotomy & $8(57)$ & $3(27)$ & $<0.005$ \\
\hline$P a, \mathrm{O}_{2} / F \mathrm{I}, \mathrm{O}_{2}$ & $271 \pm 140$ & $280 \pm 134$ & NS \\
\hline$P \mathrm{a}, \mathrm{CO}_{2} \mathrm{kPa}$ & $7.5 \pm 0.9$ & $7.6 \pm 1.2$ & NS \\
\hline $\mathrm{pH}$ & $7.39 \pm 0.01$ & $7.37 \pm 0.02$ & NS \\
\hline$V \mathrm{~T} \mathrm{~mL}$ & $340 \pm 153$ & $388 \pm 157$ & $<0.05$ \\
\hline$f \mathrm{R}$ breaths $\cdot \min ^{-1}$ & $21 \pm 7$ & $17 \pm 7$ & $<0.01$ \\
\hline$V^{\prime} \mathrm{E} \mathrm{L} \cdot \mathrm{min}^{-1}$ & $7.1 \pm 2.5$ & $6.5 \pm 1.7$ & $<0.05$ \\
\hline$f \mathrm{R} / V_{\mathrm{T}}$ & $62 \pm 40$ & $43 \pm 35$ & $<0.01$ \\
\hline PTPoes $\mathrm{cmH}_{2} \mathrm{O} \cdot \mathrm{s} \cdot \mathrm{min}^{-1}$ & $229 \pm 110$ & $179 \pm 92$ & $<0.01$ \\
\hline $\mathrm{MIP} \mathrm{cmH}_{2} \mathrm{O}$ & $40 \pm 15$ & $47 \pm 20$ & $<0.05$ \\
\hline FEV1 \% pred & $21 \pm 6$ & $35 \pm 16$ & $<0.01$ \\
\hline FVC \% pred & $32 \pm 8$ & $47 \pm 11$ & $<0.01$ \\
\hline
\end{tabular}

Data are shown as mean \pm SD or $\mathrm{n}(\%) . \mathrm{Pa}_{\mathrm{a}} \mathrm{O}_{2}$ : arterial oxygen tension; $\mathrm{FI}, \mathrm{O}_{2}$ : inspiratory oxygen fraction; $\mathrm{Pa}_{\mathrm{a}} \mathrm{CO}_{2}$ : arterial carbon dioxide tension; $V \mathrm{~T}$ : tidal volume; $f \mathrm{R}$ : respiratory frequency; $V^{\prime} \mathrm{E}$ : minute ventilation; PTPoes: pressure-time product of the inspiratory muscles; MIP: maximal inspiratory mouth pressure; FEV1: forced expiratory volume in one second; FVC: forced vital capacity.

inversion of the expiratory flow may well be considered as a sign of inspiration. Although the study protocol did not include the assessment of $V \mathrm{~T}$ by means of respiratory inductive plethysmography (RIP), four anecdotal patients in whom RIP together with Poes was assessed showed a small increase in ribcage and (mainly) abdominal displacement, thus confirming an inspiratory contraction. In conclusion, most of the events found corresponded to inspiratory acts; nevertheless, some of the $P_{\text {oes }}$ swings may be due to relaxation and further studies must be conducted in order to provide a definite interpretation.

Although noninvasive mechanical ventilation has been gaining increasing popularity to reverse acute-on-chronic respiratory failure [25], the decision to institute it is seldom based on such measurements in nonintubated patients. In ventilator-dependent patients the phenomenon of "missing" or "ineffective" efforts has been shown recently, i.e. $P$ oes swings unable to trigger the ventilator [26-28]. These ineffective efforts have also been shown during spontaneous breathing in patients during weaning [29]. High resistance to airflow, PEEPi,dyn, low elastic recoil, high ventilatory demands and short expiratory time on the ventilator have been advocated to explain this phenomenon in mechanically ventilated patients $[27,30]$. The results of the present study, showing $P_{\text {oes }}$ swings in the expiratory phases, may suggest that ineffective efforts described with mechanical ventilation may represent an amplified condition already present during spontaneous breathing. GEORGOPUOULOS and Roussos [27] proposed a finalistic explanation for the ineffective efforts: because there is no inflation during this breath, lung volume continues to decline, so that the elastic recoil is less at the beginning of the next effort and the patient is in a better position to trigger the ventilator on the next spontaneous cycle. At least theoretically, this hypothesis could be advocated to explain, at least partially, the phenomenon observed during 
spontaneous breathing in the present study: the respiratory central drive might stimulate respiratory muscles with a small inspiratory effort to allow the lung volume to decline to the previous FRC. Nevertheless, even speculatively, there are differences between the "ineffective efforts" of mechanically ventilated patients and "premature inspirations". The former are due to the impossibility of overcoming a threshold load, whereas there did not appear to be any threshold in the present patients.

Although, as a whole, the patients in group 1 did not show any greater impairment in clinical and functional condition than those in group 2 , chronically hypoxaemic patients of group 1 suffered from a greater impairment in lung function, mechanics and breathing pattern (table 4). Whether premature inspirations may influence the prognosis of these chronically hypoxaemic patients remains to be elucidated.

In conclusion, this study shows that in spontaneously breathing patients with chronic obstructive pulmonary disease recovering from an acute exacerbation of their disease, detectable activity of inspiratory muscles (as assessed by swings in oesophageal pressure) during expiration was found in more than half of the cases. Patients showing this phenomenon were not different regarding clinical, mechanic, spirometric or arterial blood gas impairment. In the subgroup of chronically hypoxaemic patients this observation was associated with a more severe level of respiratory impairment than in the hypoxaemic patients who did not present the phenomenon.

\section{References}

1. Hlastala MP, Wranne B, Lenfant C. Cyclical variation in $\mathrm{FRC}$ and other respiratory variables in resting man. $J \mathrm{Appl}$ Physiol 1973; 34: 670-676.

2. Benchitrit G, Bertrand F. A short term memory in the respiratory centers: statistical analysis. Respir Physiol 1975; 23: 147-158.

3. Brusil PJ, Waggener TB, Kronauer RE, Gulesian P. Methods for identifying respiratory oscillations disclose altitude effects. J Appl Physiol 1980; 48: 545-556.

4. Waggener TB, Frantz ID, Stark AR, Kronauer RE. Oscillation breathing patterns leading to apnoeic spells in infants. J Appl Physiol 1982; 52: 1288-1295.

5. Pack AI, Silage DA, Millman RP, Knight H, Shore ET, Chung DCC. Spectral analysis of ventilation in elderly subjects awake and asleep. J Appl Physiol 1988; 64: 1257-1267.

6. Schertel ER, Schneider DA, Adams L, Green JF. Effects of pulmonary arterial $\mathrm{PCO}_{2}$ on breathing pattern. $\mathrm{J} \mathrm{Appl}$ Physiol 1988; 64: 1844-1850.

7. Harver A, Daubenspeck JA. Human breathing pattern responses to loading with increased background impedance. J Appl Physiol 1989; 66: 680-686.

8. Modarreszadeh M, Bruce EN, Gothe B. Nonrandom variabilty in respiratory cycle parameters of humans during stage 2 sleep. J Appl Physiol 1990; 69: 630-639.

9. Clague JE, Carter J, Pearson MG, Calverley PMA. Effort sensation, chemoresponsiveness, and breathing pattern during inspiratory resistive loading. J Appl Physiol 1992; 73: 440-445.

10. Modarreszadeh $\mathrm{M}$, Bruce E. Ventilatory variability induced by spontaneous variations of $\mathrm{PaCO}_{2}$ in humans. J Appl Physiol 1994; 76: 2765-2775.

11. Garrard CS, Lane DJ. The pattern of breathing in patients with chronic airflow obstruction. Clin Sci 1979; 56: $215-$ 221.

12. Bradley CA, Fleetham JA, Anthonisen NR. Ventilatory control in patients with hypoxemia due to obstructive lung disease. Am Rev Respir Dis 1979; 120: 21-29.

13. Wolkove N, Altose MD, Kelsen SG, Cherniak NS. Respiratory control abnormalities in alveolar hypoventilation. Am Rev Respir Dis 1980; 122: 163-167.

14. Tobin MJ, Chadha TS, Jenouri G, Birch SJ, Gazeroglu HB, Sackner MA. Breathing patterns. 2. Diseased subjects. Chest 1983; 84: 286-294.

15. Loveridge B, West P, Anthonisen NR, Kryger MH. Breathing pattern in patients with chronic obstructive pulmonary disease. Am Rev Respir Dis 1984; 130: 730733.

16. Loveridge B, West P, Kryger MH, Anthonisen NR. Alteration in breathing pattern with progression of chronic obstructive pulmonary disease. Am Rev Respir Dis 1986; 134: 930-934.

17. Modarreszadeh M, Bruce EN. Long lasting ventilatory response of humans to a single breath of hypercapnia in hyperoxia. J Appl Physiol 1992; 72: 242-250.

18. American Thoracic Society Statement. Standards for the diagnosis and care of patients with chronic obstructive pulmonary disease. Am J Respir Crit Care Med 1995; 152: S77-S120.

19. European Respiratory Society Statement. Standardized lung function testing. Eur Respir J 1993; 6: 1-100.

20. Black L, Hyatt R. Maximal airway pressures: normal values and relationship to age and sex. Am Rev Respir Dis 1969; 99: 696-702.

21. Nava S, Ambrosino N, Crotti P, Fracchia C, Rampulla C. Recruitment of some respiratory muscles during three maximal inspiratory manoeuvres. Thorax 1993; 48: 702707.

22. Vitacca M, Clini E, Porta R, Foglio K, Ambrosino N. Acute exacerbations in patients with COPD requiring hospital admission: correlates of short-term outcome. Eur Respir J 1996; 9: 1487-1493.

23. Vitacca M, Clini E, Bianchi L, Ambrosino N. Acute effects of deep diaphragmatic breathing in COPD patients with chronic respiratory failure. Eur Respir J 1998; 11: 408-415.

24. Tobin MJ, Alex CG. Discontinuation of mechanical ventilation. In: Tobin MJ, ed. Principles and Practice of Mechanical Ventilation. New York, McGraw-Hill, 1994; pp. 1177-1206.

25. Ambrosino N. Noninvasive mechanical ventilation in acute respiratory failure. Eur Respir J 1996; 9: 795-807.

26. Nava S, Bruschi C, Rubini F, Palo A, Iotti G, Braschi A. Respiratory response and inspiratory effort during pressure support ventilation in COPD patients. Intensive Care Med 1995; 21: 871-879.

27. Georgopoulos D, Roussos C. Control of breathing in mechanically ventilated patients. Eur Respir $J$ 1996; 9: 2151-2160.

28. Appendini L, Purro A, Patessio A, et al. Partitioning of inspiratory muscle workload and pressure assistance in ventilator-dependent COPD patients. Am J Respir Crit Care Med 1996; 154: 1301-1309.

29. Appendini L, Zanaboni S, Patessio A, et al. Breathing pattern instability during weaning in mechanically ventilated COPD patients. Eur Respir J 1997; 10: 139s.

30. Gottfried SB. The role of PEEP or CPAP in the mechanically ventilated COPD patient. In: Roussos C, ed. The Thorax, Part C. New York, Marcel Dekker, 1995; pp. 2471-2500. 